\title{
FORMAÇÃO DE PROFESSORES DE EDUCAÇÃO FÍSICA NO PIBID: QUESTIONANDO E SUPERANDO PRÁTICAS E CONCEPÇÕES DE EDUCAÇÃO, INFÂNCIA E JUVENTUDE
}

José Milton de Lima, Márcia Regina Canhoto de Lima, Luiz Rogério Romero, Renan Silva Buccki.

Universidade Estadual Paulista - UNESP, Curso de Educação Física, Presidente Prudente, SP. E-mail: miltonlima@fct.unesp.br. Agência Financiadora: MEC/CAPES.

\section{RESUMO}

Este subprojeto de pesquisa e intervenção estabelece como objetivo central investigar e promover uma formação qualificada de professores, a partir da valorização da infância, juventude e cultura corporal no contexto escolar. A metodologia qualitativa, pautada em pressupostos da pesquisaação, possibilita a estreita relação entre teoria e prática e ação e reflexão. O referencial teórico respalda-se em autores e documentos oficiais que promovem um suporte teórico atualizado e interdisciplinar. Como resultados destacam-se a corresponsabilidade dos diferentes sujeitos no alcance dos objetivos; a adoção de atitude de autoformação; o esforço no sentido da problematização e busca de superação de concepções de educação mecânica, educação física fundamentada apenas no aspecto biofisiológico, infância como devir e juventude como etapa problemática. Enfim, conclui-se que o trabalho realizado nesse subprojeto tem-se firmado na persistência, paciência e busca de clareza de concepções e finalidades, o que vêm garantindo avanços lentos e gradativos em relação ao objetivo estabelecido.

Palavras - chave: Formação de Professores, Licenciatura, Educação Básica, Educação Física, PIBID.

\section{PHYSICAL EDUCATION TEACHER EDUCATION IN PIBID: QUESTIONING AND OVERCOMING PRACTICES AND EDUCATION CONCEPTS, INFANCY AND YOUTH.}

\begin{abstract}
This sub-project research and intervention establishes as central objective to investigate and promote a qualified teacher education from childhood appreciation, youth and physical culture in the school context. The qualitative methodology, based on action research assumptions, enables the close relationship between theory and practice and action and reflection. The theoretical reference draws upon on authors and official documents that promote an updated and interdisciplinary theoretical support. The results stand out the responsibility of different subjects in achieving the objectives; the adoption of self-tuition attitude; the effort of questioning and seeking to overcome mechanical education conceptions, based only on physical education biophysiological aspect, childhood and youth as becoming as problematic step. Finally, it is concluded that the work completed in this sub-project has been signed in the persistence, patience and search for clarity of concepts and objectives, which have ensured slow and gradual advances in the established goal.
\end{abstract}

Keywords: Teacher Education, Graduate, Basic Education, Physical Education, PIBID. 


\section{INTRODUÇÃO}

O Subprojeto PIBID: “A formação de professores de Educação Física para a Educação Básica a partir da interlocução entre infância, juventude, educação e cultura corporal de movimento", vinculado ao Curso de Educação Física da Faculdade de Ciências e Tecnologia de Presidente Prudente, parte do pressuposto de que a atuação docente está cada vez mais complexa, considerando as transformações e as exigências do contexto histórico atual. Nesta perspectiva, o professor de Educação Física deve alcançar em seu processo de formação uma ampla cultura geral e específica e também adotar, em simetria de importância, uma atitude investigativa e interdisciplinar, de maneira a valorizar as diversas dimensões que compõem e perpassam o processo de formação dos educandos: biológica, social, cultural, ética e técnico-instrumental do movimento.

O Brasil avançou em direção à democratização do acesso e da permanência dos alunos na Educação Básica de acordo com o Ministério da Educação (MEC). Atualmente, mais de 50 milhões de estudantes encontram-se matriculados nas escolas, sendo deste total $83 \%$ na rede pública de ensino. Entretanto, as avaliações nas diversas esferas: municipal, estadual e nacional revelam que o modelo educacional de natureza tradicional, propedêutico, predominante na realidade brasileira, não atende às necessidades de formação contemporâneas, voltadas à cidadania solidária, cooperativa, responsável e comprometida com o futuro da nação e do planeta.

Nesse contexto, no qual se inserem os professores da Educação Básica, o referido subprojeto, iniciado em março de 2014, incorpora-se ao Programa Institucional de Bolsa de Iniciação à Docência (PIBID) da Universidade Estadual Paulista "Júlio de Mesquita Filho" - UNESP e é financiado pela Coordenação de Aperfeiçoamento de Pessoal de Nível Superior (CAPES) e pelo MEC.

A equipe do Subprojeto do Curso de Licenciatura em Educação Física da FCT/UNESP reúne uma coordenação formada por três docentes, quatro professores supervisores da rede pública de ensino (municipal e estadual), vinte e seis bolsistas de iniciação à docência e discentes colaboradores os quais, apoiados na produção científica atual, nos documentos oficiais, e na estreita relação entre teoria e prática; ensino, extensão e pesquisa, buscam assumir outras perspectivas no processo de formação profissional, que, consolidadas, contribuirão para mudanças qualitativas e urgentes na área da Educação Física escolar.

Constata-se que as práticas educativas relacionadas à Educação Física resistem às mudanças e estão em 
descompasso com a produção científica contemporânea, em correspondência com as demais Licenciaturas, segundo Souza Neto e Hunger (2006). Portanto, o investimento no processo de formação inicial se evidencia como medida que pode gerar resultados mais significativos, tanto em médio como em longo prazo, no que concerne à qualificação do trabalho pedagógico na Educação Básica, principalmente se obtiver o estreitamento da relação entre a teoria e a prática, formação acadêmica e contexto escolar.

No contexto histórico atual, é urgente e imprescindível o debate e a implantação de outros modelos de escola, currículo, metodologias e formação, amparados na produção científica e em parâmetros atuais de qualidade e relevância social para a camada majoritária da população.

O subprojeto adota como objetivo geral principal: investigar e aprimorar o processo de formação inicial de alunos do Curso de Licenciatura em Educação Física da FCT/UNESP de Presidente Prudente e contínua dos profissionais da escola parceira, por meio do processo de estudo, intervenção e reflexão.

\section{METODOLOGIA}

A metodologia norteadora, de predominância qualitativa, pauta-se nos pressupostos da pesquisa-ação, com destaque para o trabalho colaborativo entre todos os sujeitos e a meta de promover mudanças qualitativas nas práticas educativas das escolas parceiras, mas principalmente no processo de formação dos bolsistas de ID. A pesquisa-ação, segundo Barbier (2004), apoia-se na relação estreita entre teoria e prática e, ainda, na atuação coletiva dos envolvidos. Não são apenas os pesquisadores, mas todos os participantes que buscam desvelar os problemas, levantar e buscar apoio no referencial teórico, estabelecer os objetivos, realizar intervenções e avaliações. Os registros são fundamentais e subsidiam as avaliações contínuas que demonstram se os resultados estão sendo alcançados e, também, são indispensáveis nas produções científicas e na elaboração dos relatórios.

As ações de estudo, planejamento e avaliação do subprojeto acontecem em duas reuniões de naturezas distintas. Semanalmente, ocorre a reunião exclusiva da equipe do subprojeto, sob a liderança dos coordenadores, com a participação dos supervisores, bolsistas de iniciação à docência e discentes colaboradores. Nela, são garantidos o planejamento, a elaboração dos planos de trabalho, avaliação de atividades executadas, produção de material didático-pedagógico, apresentação e análises dos dados coletados e conhecimentos resultantes do processo no seu conjunto. Quinzenalmente, sob a liderança dos 
coordenadores, os bolsistas de iniciação à docência e discentes colaboradores participam da Reunião do Grupo de Pesquisa: Cultura Corporal, Saberes e Fazeres com o intuito de aprofundamento teóricometodológico, em parceria com discentes de iniciação científica, outros graduandos de projetos de extensão, mestrandos, doutorandos e professores em exercício.

Junto com as atividades destacadas, os bolsistas frequentam semanalmente as escolas e acompanham ou atuam nas aulas com os seus supervisores, fazendo observações, intervenções quando solicitados e registrando os aspectos relevantes percebidos. Entre os bolsistas de ID é feita uma escala para que sempre um deles esteja presente nas reuniões semanais das escolas, acompanhando as discussões, destaque para as reuniões de conselho de classe e escola, planejamento e atividade de trabalho pedagógico coletivo (ATPC). Pretende-se com essa participação, que os alunos conheçam a escola nas suas múltiplas dimensões, compreendendo que o trabalho pedagógico não se restringe apenas a sala de aula, mas perpassa as diversas atividades que acontecem no interior da escola.

\section{PRESSUPOSTOS TEÓRICOS}

O processo de formação instituído no subprojeto de Educação Física tem procurado ser coerente com a metodologia norteadora e com a produção científica atual, buscando superar modelos autoritários, reducionistas e tecnicistas, a partir dos quais os coordenadores determinariam as ações e os supervisores e bolsistas atuariam como executores, prestando conta das tarefas definidas. Para tanto, bases teóricas são levantadas e discutidas, colaborando para reafirmar concepções e práticas que gerem um contexto dinâmico de estudo, ação, reflexão, divisão de responsabilidades e aprendizagens recíprocas.

Diversas abordagens têm sido estudadas, dentre outras, destacamos a abordagem Psicomotora (MOLINARI; SENS, 2003), Desenvolvimentista (TANI, 1987), Construtivista (FREIRE, 1989), CríticoSuperadora (SOARES et al., 1992) e PósCrítica (GARCIA; NUNES, 2009). Ao estudarem, analisarem e discutirem sobre cada uma das abordagens, os bolsistas de ID ampliam a base teórica sobre a Educação Física no seu processo histórico, compreendendo os fundamentos teóricos que alicerçam cada uma dessas vertentes e seus elementos didáticos: finalidades, conteúdos, metodologia, relação interpessoal e avaliação. A busca por este conhecimento inicial, subsidia as ações dos bolsistas, em parceria, com os supervisores. A indicação, para que estes estudos se tornassem prioritários, foi enfatizada pelos supervisores que alertaram sobre as dificuldades que 
tinham em expor a sua proposta de trabalho pedagógico, pois faltavam aos bolsistas de ID conhecimentos prévios sobre a área, dificultando assim o processo de comunicação e de formação compartilhada.

Outra preocupação central, assumida no processo de formação da equipe do subprojeto, refere-se à problematização e à construção de novas bases em relação à concepção de criança e de jovem no contexto escolar. Para tanto, estudos têm sido realizados, nos diversos momentos proporcionados, em especial nas reuniões do Grupo de Pesquisa, com o intuito de questionar e superar concepções que tomam a criança e o jovem como adulto em miniatura ou ser em "devir". Autores que investigam e analisam concepções de infância, destaque para Ariès (2011) e, em especial, Sarmento (2004), representando a Sociologia da Infância, esclarecem as origens históricas das diversas concepções e possibilitam adoção de uma concepção que enxerga a infância como categoria social e a criança como sujeito histórico e de direitos, produtora de cultura, com especificidade e identidade próprias, marcas que a distinguem de pessoas de outras categorias sociais: jovens e adultos.

Na mesma direção, têm se discutido e analisado o jovem que frequenta as séries finais do Ensino Fundamental e do Ensino Médio, visto pelo senso comum como sujeito problema, em razão da fase da adolescência em que se situa. Autores, em especial da Sociologia da Juventude, destaque para Carrano (2009), Dayrell (2007), Paes (1990, 2003), colaboram para problematizar esta visão e assim assumir perspectivas que concebem a juventude como categoria social e o jovem como sujeito de características, culturas e identidade próprias. Sendo fundamental que as escolas revejam concepções naturalistas, limitadoras e assumam novas perspectivas respaldadas pelas produções científicas atuais, transformando o contexto escolar em um espaço mais atraente, inclusivo, formativo, de múltiplas linguagens e culturas.

Além do aprofundamento teórico sobre a Educação Física escolar, concepção de criança e jovem, outros temas considerados basilares, também, são aprofundados e discutidos. Primeiramente, ressaltamos os estudos sobre o PIBID como uma política de formação e valorização de professores e a perspectiva de formação profissional assumida pelo programa. Entre outros textos estudados e analisados, destacamos documentos oficiais sobre o PIBID (BRASIL, 2004), o artigo de Felício (2014), intitulado: “O PIBID como 'terceiro espaço' de formação de professores" e o de Borges (2014), denominado de "Profissionalidade docente: da prática à práxis". 
Tais estudos têm contribuído para a compreensão do PIBID como uma política de formação e valorização de professores, cujos resultados só serão alcançados se cada um dos componentes da equipe assumir o seu papel com compromisso, responsabilidade e clareza da sua importância social. Neste sentido, busca-se superar a visão mecânica e de racionalidade técnica de formação que se caracteriza por papéis hierárquicos e muito bem definidos.

Os artigos de Felício (2014) e Borges (2014) contribuem para se repensar tais perspectivas e se adotar outras proposições que ressaltam a superação da dicotomia entre teoria e prática, universidade e escola e a busca de corresponsabilidade no processo de ensino-aprendizagem e de formação. Felício (2014), apoiada em na concepção de Zeichner (2010), propõe a constituição do PIBID como "terceiro espaço", cujo processo de formação supera os modelos hierárquicos e torna este espaço mais híbrido. Nele, encontram-se os sujeitos da universidade (coordenadores) e das escolas (supervisores) componentes do PIBID, onde estabelecem parcerias e são corresponsáveis pelo processo de formação dos bolsistas de ID. Estes por sua vez, não são sujeitos passivos no processo, mas pautados em Borges (2014, p. 50), são esclarecidos sobre a complexidade da profissão docente, cuja formação é contínua e ininterrupta. Portanto, o processo de formação se caracteriza como inacabado e não se divide entre formadores e formandos, mas em pessoas que se encontram em contextos colaborativos, com fundamentos e experiências distintas e se pautam no exercício de uma reflexividade crítica sobre a prática, buscando o incremento de novos saberes.

\section{RESULTADOS E DISCUSSÕES}

O subprojeto PIBID de Educação Física conta atualmente com trinta alunos do Curso de Educação Física. Este contingente traz discentes com múltiplos interesses e expectativas junto ao PIBID. Ao serem colocados frente às finalidades e pressupostos teóricos do subprojeto, revelam diferentes posturas e posicionamentos. Independente dos bolsistas de iniciação à docência que se identificam ou não com a licenciatura e a formação para a docência, um grande desafio tem se colocado para a coordenação e supervisão. A maioria dos bolsistas de ID, em razão das marcas que estão gravadas na sua história como alunos, revela dificuldades em assumir o seu processo de formação como protagonista, esperando ações definidas pelos formadores para que possa executar, sem grandes esforços e aplicação. Neste sentido, estão sendo, insistentemente, questionadas concepções de formação e educação tradicional e tecnicista, acima expostas, com 
o intuito de colocar em xeque posturas passivas e de buscar novas referências que gerem outros suportes teóricos e posicionamentos ativos e críticos.

Procedimentos metodológicos, também, são adotados, visando garantir oportunidades de participação e corresponsabilidade, entre outros, destacamse as discussões nos grupos de intervenções, incentivo as expressões de opiniões, as oportunidades de narrativas embasadas em suportes teóricos, exigências de registros individuais e coletivos, participação na elaboração e apresentação de trabalhos em eventos científicos.

O resultado principal que se busca é que todos se apropriem das bases teóricas discutidas e que assumam as responsabilidades com 0 processo de formação individual e coletivo. Sendo assim, as ações vivenciadas, as situações de estudo, intervenção, reflexão e discussão tornam-se meios de formação coletiva, a partir das quais todos possam ser tocados, influenciados e comecem a questionar suas representações, concepções e visões, abrindo-se para as outras perspectivas mais atualizadas e assumidas pelo subprojeto.

A presença dos supervisores, semanalmente na universidade, tem sido um fator decisivo para o alcance dos resultados, pois se observa que a base teórica discutida, também, tem influenciado as suas competências e exigências em relação ao PIBID. Entre outras, a principal a ser destacada é o papel de co-formador dos bolsistas de ID junto ao subprojeto, compreendendo as implicações geradas a partir deste posicionamento e adotando posturas peculiares ou mesmo de consenso entre participantes. A relação de parceria instalada incentiva e valoriza as iniciativas dos bolsistas de ID que buscam conteúdos e meios para aprimorar, enriquecer e diversificar a prática educativa. Este processo de troca e parceira gera repercussões na prática educativa, tornando as aulas de Educação Física nas escolas mais interessantes e significativas para os alunos, trazendo também a sensação de realização e reconhecimento aos bolsistas de ID. Este aspecto é fundamental, pois o bolsista de iniciação à docência percebe que o trabalho docente também tem seus momentos de alegrias e realizações.

\section{CONCLUSÕES}

Tendo em vista o compromisso e empenho apresentados pelos integrantes do Subprojeto PIBID, o respaldo oferecido pela UNESP e pelas escolas parceiras, os resultados revelam que ações efetivadas promovem avanços qualitativos no processo de formação de todos os envolvidos, mesmo que em níveis distintos. É consenso entre os bolsistas de iniciação à docência que a 
oportunidade semanal de estar nas escolas, semanalmente, inseridos no ambiente escolar, vivenciando experiências ao lado dos seus pares e supervisores, é um aspecto a ser ressaltado do programa, pois proporciona a relação teoria e prática, carregando de significados conteúdos aprendidos na universidade e concomitantemente as experiências vivenciadas nas escolas.

Enfim, as análises dos dados coletados apontam e sublinham a importância do subprojeto PIBID na formação dos licenciandos em Educação Física, todavia, o processo pode ser aprimorado com o aprofundamento teórico, a problematização de concepções e a opção consciente de novas atitudes.

Cabe, por fim destacar, que o arcabouço teórico, as atividades dos bolsistas de ID, em parceria com os supervisores do Subprojeto, promovem também

\section{REFERÊNCIAS}

ARIÈS, P. História social da criança e da família. 2. ed. Rio de Janeiro: LTC, 2011.

BARBIER, R. A pesquisa-ação. Trad. Lucie Didio. Brasília: Líber Livro, 2004.

BORGES, M. L. Profissionalidade docente: da prática à práxis. Revista Investigar Em Educação, 2a sér., n. 2, 2014.

BRASIL. Ministério da Educação. Ampliação do ensino fundamental para nove anos: relatório do programa. Brasília: MEC, 2004. Disponível repercussões positivas nas aulas oferecidas para as crianças e aos jovens nas intervenções. Os supervisores afirmam que a presença dos bolsistas os motivam a aprimorar e a diversificar o seu trabalho, além disso, incentivam os futuros professores a levantar novos conteúdos que enriquecem a prática educativa, aprimorando a educação oferecida nas escolas parceiras.

Os resultados positivos são animadores, todavia, o trabalho é árduo na busca de superação de concepções arcaicas de educação, criança e jovem, a valorização dos conteúdos da Cultura Corporal de Movimento como imprescindíveis para uma formação global e holística dos educandos.

<http://portal.mec.gov.br/seb/arquivos/pdf/ 9anosrelat.pdf $>$. Acesso em: 13 mar. 2010.

CARRANO, P. Identidades culturais juvenis e escolas: arenas de conflitos e possibilidades. Diversia, n.1, abr. 2009, p. 159-184.

DAYRELL, J. A escola faz a Juventude: reflexões sobre a socialização juvenil. Educação \& Sociedade, v. 28, n. 100, out., $2007 . \quad$ http://dx.doi.org/10.1590/S0101$\underline{73302007000300022}$

FELÍ́CIO, H. M. dos S. O PIBID como "terceiro espaço" de formação de professores. Rev. 
Diálogo Educ., Curitiba, v. 14, n. 42, p. 415434, maio/ago. 2014.

FREIRE, J.B. Educação de corpo inteiro: teoria e prática da Educação Física. São Paulo: Scipione, 1989.

GARCIA, M. N.; NUNES, M. L. F. Educação física, cultura e currículo. [S.I.]: Phorte, 2009.

MOLINARI Â. M. DA P.; SENS, S. M. $A$ Educação física e sua relação com a psicomotricidade. Rev. PEC, Curitiba, v.3, n.1, p.87-93, jul. 2002-jul. 2003. http://www.pucrs.campus2.br/ brandt/edfisi carelacaopsicomotricidade.pdf

PAES, J. M. A construção sociológica da juventude, alguns contributos. Análise Social, vol. 25, n. 105-106, 139-165, 1990.

Culturas Juvenis. Lisboa: Imprensa Nacional Casa da Moeda, 2003.

SARMENTO, M. J. As culturas da infância nas encruzilhadas da segunda modernidade. In: SARMENTO, M. J.; CERISARA, A. B. Crianças e miúdos: perspectivas sociopedagógicas da infância e educação. Porto: Ed. Asa, 2004. p. 9-34.

SOARES, C. L. et al. Metodologia do Ensino de Educação Física. São Paulo: Cortez, 1992.

SOUZA NETO, S.; HUNGER, D. (Org.). A formação profissional em educação

física: estudos e pesquisa. Rio Claro: Biblioética, 2006.

TANI, G. Educação física na pré-escola e nas quatro primeiras séries do ensino de primeiro grau: uma abordagem de desenvolvimento. Revista Kinesis, n. 3, p. 19-41. 1987.

ZEICHNER, K. Repensando as conexões entre a formação na universidade e as experiências de campo na formação de professores em faculdades e universidade. Educação, v. 35, n. 3, p. 479-504, maio/ago. 2010.
Recebido para publicação em 06/08/2015 Revisado em 28/08/2015

Aceito em 02/09/2015 